\title{
Clinical significance of L-type amino acid transporter 1 expression as a prognostic marker and potential of new targeting therapy in biliary tract cancer
}

Kyoichi Kaira ${ }^{1,11,12^{*}}$, Yutaka Sunose ${ }^{2 \dagger}$, Yasuhiro Ohshima ${ }^{3^{* \dagger}}$, Noriko S Ishioka ${ }^{3}$, Kazuhisa Arakawa ${ }^{4}$, Tetsushi Ogawa ${ }^{4}$, Noriaki Sunaga ${ }^{1}$, Kimihiro Shimizu ${ }^{2}$, Hideyuki Tominaga ${ }^{5}$, Noboru Oriuchi ${ }^{6,7}$, Hideaki Itoh $^{8}$, Shushi Nagamori ${ }^{9}$, Yoshikatsu Kanai ${ }^{9}$, Aiko Yamaguchi ${ }^{10}$, Atsuki Segawa ${ }^{11}$, Munenori Ide ${ }^{11}$, Masatomo Mori ${ }^{1}$, Tetsunari Oyama ${ }^{11}$ and Izumi Takeyoshi

\begin{abstract}
Background: The expression of L-type amino acid transporter 1 (LAT1) has been described to play essential roles in tumor cell growth and survival. However, it remains unclear about the clinicopathological significance of LAT1 expression in biliary tract cancer. This study was conducted to determine biological significance of LAT1 expression and investigate whether LAT1 could be a prognostic biomarker for biliary tract cancer.

Methods: A total of 139 consecutive patients with resected pathologic stage I-IV biliary tract adenocarcinoma were retrospectively reviewed. Tumor specimens were stained by immunohistochemistry for LAT1, Ki-67, microvessel density determined by CD34, and p53; and prognosis of patients was correlated. Biological significance of LAT1 expression was investigated by in vitro and in vivo experiments with LAT inhibitor, 2-aminobicyclo-(2,2,1)-heptane-2-carboxylic acid $(\mathrm{BCH})$ using cholangiocarcinoma cell line.
\end{abstract}

Results: In total patients, high LAT1 expressions were recognized in 64.0\%. The expression of LAT1 was closely correlated with lymphatic metastases, cell proliferation and angiogenesis, and was a significant indicator for predicting poor outcome after surgery. LAT1 expression was a significant independent predictor by multivariate analysis. Both in vitro and in vivo preliminary experiments indicated that BCH significantly suppressed growth of the tumor and yielded an additive therapeutic efficacy to gemcitabine and 5-FU.

Conclusions: High expression of LAT1 is a promising pathological marker to predict the outcome in patients with biliary tract adenocarcinoma. Inhibition of LAT1 may be an effective targeted therapy for this distressing disease.

Keywords: LAT1, Biliary tract cancer, Amino acid transporter, Prognostic factor, BCH

\footnotetext{
*Correspondence: kkaira1970@yahoo.co.jp; ohshima.yasuhiro@jaea.go.jp

${ }^{\dagger}$ Equal contributors

'Department of Medicine and Molecular Science, Gunma University Graduate School of Medicine, Showa-machi, Maebashi, Gunma, Japan

${ }^{3}$ Medical Radioisotope Application Group, Quantum Beam Science Directorate, Japan Atomic Energy Agency, Watanuki, 370-1292 Takasaki, Gunma, Japan Full list of author information is available at the end of the article
} 


\section{Background}

Biliary tract cancer is a relatively uncommon malignant neoplasm and is one of the aggressive malignancy with poor prognosis [1]. Gallbladder carcinoma and extrahepatic bile ducts carcinoma (cholangiocarcinoma) are the most common biliary tract cancer and cholangiocarcinoma is classified into intrahepatic and extrahepatic disease according to its anatomical location within the biliary tree [2]. Surgical resection remains the only potentially curative therapeutic option, however, more than half of patients present with unresectable disease. Even if curative resection can be performed, the 5-year overall survival is $20-32 \%$ for intrahepatic cholangiocarcinoma, $30-42 \%$ for hilar cholangiocarcinoma, and $18-54 \%$ for distal cholangiocarcinoma [3-5]. Although many patients may receive adjuvant chemotherapy to improve chance of cure, there is no established standard chemotherapy. In advanced biliary tract cancer, combination chemotherapy with gemcitabine and a platinum-based agent is regarded as a standard treatment, however, the prognosis after treatment remains dismal [6]. To date, the patients with biliary tract cancer lack a survival benefit if treated with chemotherapy or radiation therapy. Thus, we need a new effective therapy to improve the survival of patients. To improve the outcome of therapy, therefore, clinical markers that can predict response to the specific therapy and the prognosis should be established.

Amino acid transporters are essential for growth and proliferation of normal cells as well as transformed cells $[7,8]$. L-type amino acid transporter 1 (LAT1) is one of the L-type amino acid transporters, and transports large neutral amino acids such as leucine, isoleucine, valine, phenylalanine, tyrosine, tryptophan, methionine and histidine $[9,10]$. LAT1 requires covalent association with the heavy chain of 4F2 cell surface antigen (CD98) for its functional expression in plasma membrane [9]. LAT1 has been closely associated with cancerous or proliferative cells, and previous studies have shown LAT1 to be highly expressed in proliferating tissues, many tumor cell lines and primary human tumors [10-17]. In human tumor tissues, LAT1 expression has a close relationship with cell proliferation, angiogenesis and cell cycle regulator $[18,19]$. Recently, the expression of LAT1 has been described to be a significant factor indicating a poor outcome in various human cancers [12-17]. Moreover, the potential of targeting therapy for LAT1 had been suggested in tumor cell lines by the inhibition of LAT1 using 2-aminobicyclo-(2,2,1)-heptane-2-carboxylic acid $(\mathrm{BCH})[20,21]$. However, it remains unknown whether LAT1 expression has a clinical and pathological significance in patients with biliary tract cancer.

In the present study, we examined LAT1 expression in the resected tissue specimens to evaluate the clinicopathological and prognostic significance of LAT1 in patients with biliary tract cancer. LAT1 expression was correlated with pathological biomarkers such as cellular proliferation, cell cycle regulator (p53) and angiogenesis. In addition, in vitro and in vivo animal studies were performed to investigate the potential of LAT1 as a therapeutic biomarker in a novel targeting therapy.

\section{Methods}

\section{Patients}

We analyzed 157 consecutive patients with biliary tract adenocarcinoma who underwent surgical resection at Gunma University Hospital and Maebashi Red Cross Hospital between September 2000 and October 2011. Ten patients who received induction chemotherapy or radiation therapy were excluded. In all cases, magnetic resonance cholangiopancreatography (MRCP) and endoscopic retrograde cholangiopancreatography (ERCP) were performed before surgical resection, and pancreatic ductal adenocarcinoma and ampullary carcinoma were excluded from the study. The specimens from eight patients were not available. All surgical specimens were reviewed and classified according to the WHO classification by an experienced pathologist who was unaware of clinical or imaging findings. Patients with pathological diagnosis other than adenocarcinoma were excluded. In total, 139 patients were analyzed in the study. The study population consisted of patients with extrahepatic cholangiocarcinoma (EHCC), intrahepatic cholangiocarcinoma (IHCC) and gallbladder carcinoma (GB). Pathologic tumor-node-metastasis (TNM) stages were established using the International System for Staging bile duct cancer adopted by the American Joint Committee on Cancer and the Union Internationale Centre le Cancer [22].

We also analyzed a control group of 16 patients with surgically resected benign biliary tract lesions. Immunohistochemical staining of samples from these 16 patients was performed and compared with that of biliary tract cancer. The pathological diagnosis of the control group was as follows: 6 patients with cholesterol polyp, 4 patients with hyperplastic polyp, 3 patients with xanthogranulomatous chlecystitis and 3 patients with adenomyomatosis. This study was approved by the institutional review board of Gunma University Hospital (ethical committee for clinical studies-Gunma University faculty of Medicine) and written informed consent was obtained from all of the patients or their families who participated to this study.

\section{Immunohistochemical staining}

LAT1 expression was determined by immunohistochemical staining with LAT1 antibody $(2 \mathrm{mg} / \mathrm{mL}$, anti-human monoclonal mouse antibody, 4A2, provided by $\mathrm{Dr} \mathrm{H}$. Endou [J-Pharma, Tokyo, Japan], dilution; 1:3200). The production and characterization of the LAT1 antibody 
has previously been described [15]. The detailed protocol for immunostaining was published elsewhere [16]. The LAT1 expression score was assessed by the extent of staining as follows: $1, \leq 10 \%$ of tumor area stained; 2 , $11-25 \%$ stained; $3,26-50 \%$ stained; and $4, \geq 51 \%$ stained. The tumors in which stained tumor cells were scored as 3 or 4 were defined as high expression.

For CD34, Ki-67 and p53, immunohistochemical staining was performed according to the procedures described in previous reports $[23,24]$. The following antibodies were used: mouse monoclonal antibodies against CD34 (Nichirei, Tokyo, Japan, 1:800 dilution), Ki-67 (Dako, Glostrup, Denmark, 1:40 dilution), and p53 (D07; Dako, 1:50 dilution). The number of CD34-positive vessels was counted in four selected hot spots in a $\mathrm{x} 400$ field $\left(0.26 \mathrm{~mm}^{2}\right.$ field area). Microvessel density (MVD) was defined as the mean count of microvessels per $0.26 \mathrm{~mm}^{2}$ field area. The median number of CD34-positive vessels was evaluated, and the tumors in which stained tumor cells made up more than each median value were defined as high expression. For p53, microscopic examination for the nuclear reaction product was performed and scored, and p53 expression in greater than $10 \%$ of tumor cells was defined as positive expression [24]. For, Ki-67, a highly cellular area of the immunostained sections was evaluated. All epithelial cells with nuclear staining of any intensity were defined as high expression. Approximately 1000 nuclei were counted on each slide. Proliferative activity was assessed as the percentage of Ki-67-stained nuclei (Ki-67 labeling index) in the sample. The median value of the Ki-67 labeling index was evaluated, and the tumor cells with greater than the median value were defined as high expression. The sections were assessed using a light microscopy in a blinded fashion by at least two of the authors.

\section{Biochemical materials}

Dulbecco's modified Eagle's medium (DMEM), penicillin and streptomycin were purchased from WAKO Pure Chemical Industries (Osaka, Japan). $\mathrm{BCH}$ was obtained from NARD Institute (Hyogo, Japan). 3-[4,5-dimethyl-2thiazolyl]-2,5-diphenyl- $2 H$-tetrazolium bromide (MTT) were purchased from Dojindo Laboratories (Kumamoto, Japan). All other chemicals used were of the highest purity available.

\section{Cell culture}

A human cholangiocarcinoma cell lines, HuCCT1 (JCRB0425), OZ (JCRB1032), and HuH28 (JCRB0426) were purchased from the Health Science Research Resources Bank (Osaka, Japan) [25-27], and routinely maintained in DMEM containing 10\% heat-inactivated fetal bovine serum (AusGeneX, Loganholme, QLD, Australia), penicillin (100 units/ml), streptomycin
$(100 \mu \mathrm{g} / \mathrm{ml})$ and $\mathrm{L}$-glutamine $(2 \mathrm{mM})$ at $37^{\circ} \mathrm{C}$ in $5 \%$ $\mathrm{CO}_{2}, 95 \%$ air.

\section{Expression of LAT mRNA in cholangiocarcinoma}

Previously, 4 subtypes of L-type amino acid transporter (LAT1-4) have been identified [8,23-30]. Realtime RTPCR analysis was performed to determine the expression of LAT1, LAT2, LAT3, and LAT4 mRNA in cholangiocarcinoma cell line. Total RNA was isolated from HuCCT1 cells using a Fast Pure RNA kit (Takara Bio, Shiga, Japan). The first-strand complement DNA was synthesized from $0.5 \mu \mathrm{g}$ of total RNA with PrimeScript Reverse Transcriptase (Takara Bio). The sequences of specific primers were shown in Additional file 1: Table S1 (online only). The realtime PCR analysis was performed by first incubating each complement DNA sample with the primers $(0.5 \mu \mathrm{M}$ each $)$ and Thunderbird SYBR qPCR Mix (Toyobo, Osaka, Japan). Amplification was carried out for 40 cycles $\left(95^{\circ} \mathrm{C}\right.$ for $15 \mathrm{~s}, 60^{\circ} \mathrm{C}$ for $\left.30 \mathrm{~s}\right)$ with PikoReal thermal cycler (Thermo Fisher Scientific, Waltham, MA). The data was analyzed according to $2_{\mathrm{T}}^{-\Delta \Delta \mathrm{C}}$ method (internal control: $\beta$-actin, calibrator: LAT1).

\section{Suppression of cell proliferation with LAT1 inhibition}

Cells were plated at a concentration of $1 \times 10^{3}$ cells/well in 96-well plates and incubated in the growth medium for $24 \mathrm{~h}$. At first, in order to determine the effect of LAT1 inhibition on cholangiocarcinoma, HuCCT1 cells were treated with $\mathrm{BCH}(0.1,1,2,3,5,10,20,30$, or $100 \mathrm{mM}$ ) and incubated for 6 days. Next, the effect of LAT1 inhibition on the antitumor activity of gemcitabine (GEM, Eli Lilly, Indianapolis, IN) or 5fluorouracil (5-FU, Kyowa Hakko Kirin, Shizuoka, Japan) was evaluated. Cells were incubated for 6 days with GEM $(10,20,50$ or $100 \mathrm{nM})$ or 5 -FU $(1,10$, or $100 \mu \mathrm{M})$ in a presence or absence of $10 \mathrm{mM} \mathrm{BCH}$. Then, cells were incubated with $0.5 \mathrm{mg} / \mathrm{ml}$ MTT for $4 \mathrm{~h}$ at $37^{\circ} \mathrm{C}$. The resulting formazan was solubilized, and the absorbance was read at $590 \mathrm{~nm}$ with a microtiter plate reader (Vmax; Molecular Devices, Sunnyvale, CA).

\section{Suppression of amino acid uptake into cells with LAT1 inhibition}

Inhibition of amino acid transport by $\mathrm{BCH}$ was examined using $\left[{ }^{14} \mathrm{C}\right] \mathrm{L}$-leucine (Perkin-Elmer Life Sciences, Boston, MA), one of the substrates of LATs [31]. HuCCT1 cells $\left(1.0 \times 10^{5}\right.$ cells/well $)$ were plated in the 24-well plates and incubated in the growth medium for $24 \mathrm{~h}$. After the incubation, the cells were washed three times with sodiumfree Hunk's balanced salt solution $\left(\mathrm{Na}^{+}\right.$-free HBSS; $137 \mathrm{mM}$ choline chloride, $5.3 \mathrm{mM} \mathrm{KC1}, 1.3 \mathrm{mM} \mathrm{CaCl}_{2}$, $0.49 \mathrm{mM} \mathrm{MgCl}, 0.41 \mathrm{mM} \mathrm{MgSO}{ }_{4}, 0.35 \mathrm{mM} \mathrm{K}_{2} \mathrm{HPO}_{4}$, $0.44 \mathrm{mM} \mathrm{KH} \mathrm{PO}_{4}, 4.2 \mathrm{mM} \mathrm{KHCO} 3,5.6 \mathrm{mM}$ D-glucose (pH 7.4)). The cells were incubated in $\mathrm{Na}^{+}$-free HBSS 
containing various concentration of $\mathrm{BCH}(0.01,0.03,0.1$, $0.3,1$, or $3 \mathrm{mM}$ ) for $10 \mathrm{~min}$ at $37^{\circ} \mathrm{C}$, and then, the supernatant was replaced by $\mathrm{Na}^{+}$-free HBSS containing $1 \mu \mathrm{M}$ $\left[{ }^{14} \mathrm{C}\right] \mathrm{L}$-leucine and $\mathrm{BCH}$ with the same concentration $(0.01,0.03,0.1,0.3,1$, or $3 \mathrm{mM})$. At $1 \mathrm{~min}$ after treatment with $\left[{ }^{14} \mathrm{C}\right] \mathrm{L}$-leucine, uptake was terminated by removing the uptake solution followed by washing three times with ice-cold $\mathrm{Na}^{+}$-free HBSS. Cells were solubilized with $0.1 \mathrm{~N}$ $\mathrm{NaOH}$, and radioactivity was measured by liquid scintillation spectrometry (AccuFLEX LSC-7200, Hitachi Aloka Medical, Tokyo, Japan).

\section{Immunoblotting}

Cells were dissolved in sample buffer (25\% glycerin, 1\% SDS, $62.5 \mathrm{mM}$ Tris- $\mathrm{Cl}, 10 \mathrm{mM}$ dithiothreitol) and incubated at $65^{\circ} \mathrm{C}$ (LAT1) or $95^{\circ} \mathrm{C}$ (CD98 and $\beta$-actin) for $15 \mathrm{~min}$. Aliquots of samples containing $40 \mu \mathrm{g}$ of protein were analyzed by $10 \%$ SDS-polyacrylamide gel electrophoresis and transferred onto a polyvinylidene difluoride membrane. Blots were incubated at $4^{\circ} \mathrm{C}$ overnight in $10 \mathrm{mM}$ Tris- $\mathrm{HCl}, 100 \mathrm{mM} \mathrm{NaCl}, 0.1 \%$ Tween 20, pH 7.5 (TBST), with 5\% skim milk and then with rabbit antiLAT1 C-terminus antibody $(1: 5,000)$ [32], rabbit antiCD98 antibody (1:200; Santa Cruz Biotechnology) or rabbit anti-actin antibody (1:1,000; Cell Signaling Technology, Beverly, MA) at $4^{\circ} \mathrm{C}$ overnight. After having been washed with TBST, the blots were incubated with goat horseradish peroxidase conjugated anti-rabbit IgG antibody (1:20,000; Cell Signaling Technology) for $1.5 \mathrm{~h}$ at room temperature. The blots were further washed with TBST, and specific proteins were visualized by using enhanced chemiluminescence western blotting detection reagents (GE Healthcare, Piscataway, NJ).

\section{Anti-tumor effect of LAT1 inhibition}

Five-week-old male BALB/ c nude mice were purchased from CLEA Japan (Tokyo, Japan). The animals were cared for and treated in accordance with the guidelines of the animal care and experimentation committee at our facility. HuCCT 1 cells $\left(1 \times 10^{7}\right.$ cells) were inoculated s.c. into the flank of the mice. After inoculation, the longer and shorter diameters of the tumor were measured with caliper and tumor volume was calculated by the following formula: Tumor volume $\left(\mathrm{mm}^{3}\right)=$ longer diameter $\mathrm{x}$ (shorter diameter) ${ }^{2} / 2$. After tumor volumes had reached approximately $100 \mathrm{~mm}^{3}$, the mice were divided into control group and treatment group $(n=10)$. Saline or $\mathrm{BCH}(200 \mathrm{mg} / \mathrm{kg})$ was intravenously administered once daily from the day of grouping (day 0) for 14 days. Tumor volume and body weight were measured two or three times a week for 42 days. No animals were excluded and no animals died due to toxicity.

To evaluate the effect of $\mathrm{BCH}$ on the tumor glucose metabolism, positron emission tomography (PET) imaging of tumor-bearing mice was performed with $\left[{ }^{18} \mathrm{~F}\right]$ fluoro-2-deoxyglucose $\left({ }^{18} \mathrm{~F}-\mathrm{FDG}\right)$ using an animal PET scanner (Inveon, Siemens, Knoxville, TN). ${ }^{18} \mathrm{~F}$ was produced using a cyclotron (CYPRIS HM-18, Sumitomo Heavy Industries, Tokyo, Japan) and ${ }^{18}$ F-FDG was synthesized in our facility. Mice for PET imaging were randomly selected from treatment group and control. Before imaging, mice were fasted for $8 \mathrm{~h}$ and had free access to water. ${ }^{18}$ F-FDG (10 MBq) was administered intravenously into mice followed by $10 \mathrm{~min}$ data acquisition at $2 \mathrm{~h}$ after the administration. Mice were maintained under isoflurane anesthesia during the administration, uptake period and PET scan. For analysis of the image, region of interest (ROI) was drawn around the edge of the tumor activity using ASIPro VM (CTI Concorde Microsystems, Knoxville, TN). The maximum and median activities were recorded. Standardized uptake value (SUV) was used to evaluate glucose metabolism of the tumor. SUV was calculated as follows: SUV $=$ ROI activity $(\mathrm{kBq} / \mathrm{ml}) /$ injected dose (MBq) x body weight (kg). SUV max and SUV 50\% were compared between $\mathrm{BCH}$-treated mice and control mice.

\section{Statistical analysis}

Probability values of $<0.05$ indicated a statistically significant difference. Results are expressed as mean \pm SEM. The significance of difference was determined by Student's t-test. The correlation between different variables was analyzed using the nonparametric Spearman's rank test. The Kaplan-Meier method was used to estimate survival as a function of time, and survival differences were analyzed by the log-rank test. Overall survival (OS) was determined as the time from tumor resection to death from any cause. Progression-free survival (PFS) was defined as the time between tumor resection and the first disease progression or death. Multivariate analyses were performed using stepwise Cox proportional hazards model to identify independent prognostic factors. Statistical analysis was performed using GraphPad Prism 4 software (Graph Pad Software, San Diego, CA, USA) and JMP 8 (SAS, Institute Inc., Cary, NC, USA) for Windows.

\section{Results}

\section{Patient's demographics}

One hundred thirty-nine patients with biliary tract adenocarcinoma were analyzed (EHCC, $\mathrm{n}=89 ; \mathrm{GB}, \mathrm{n}=30$; and IHCC, $n=20$ ). Clinicopathologic results stratified by tumor location are listed in Table 1 . The age of the patients ranged from 42 to 86 years, and the median age was 71 years. Most tumors $(n=126,90.6 \%)$ were pathological stages I to III. Fifty-one patients had received postoperative adjuvant chemotherapy with GEM, S-1 (Taiho Pharmaceutical Co., Ltd, Tokyo, Japan) or oral administration of tegafur (a fluorouracil derivative 
Table 1 Patient's characteristics and pathological findings

\begin{tabular}{|c|c|c|c|c|c|c|c|c|c|c|}
\hline \multirow{2}{*}{ Characteristic } & \multicolumn{2}{|c|}{ All patients $(n=139)$} & \multicolumn{2}{|c|}{$\operatorname{EHCC}(n=89)$} & \multicolumn{2}{|l|}{$\mathrm{GB}(n=30)$} & \multicolumn{2}{|c|}{ IHCC $(n=20)$} & \multicolumn{2}{|c|}{ Control $(n=16)$} \\
\hline & No. of patients & $\%$ & No. of patients & $\%$ & No. of patients & $\%$ & No. of patients & $\%$ & No. of patients & $\%$ \\
\hline Median age (years) & 71 & & 71 & & 74 & & 64 & & 62 & \\
\hline Male & 86 & 61.8 & 65 & 73.0 & 8 & 26.7 & 13 & 65.0 & NA & \\
\hline $\mathrm{R} 0$ resection & 67 & 48.2 & 38 & 42.7 & 19 & 47.4 & 10 & 50.0 & NA & \\
\hline Poorly differentiated & 33 & 23.7 & 18 & 20.2 & 3 & 10.0 & 12 & 60.0 & NA & \\
\hline Lymphatic permeation & 111 & 79.8 & 74 & 83.1 & 23 & 76.7 & 14 & 70.0 & NA & \\
\hline Vascular invasion & 93 & 66.9 & 66 & 74.1 & 16 & 53.3 & 12 & 60.0 & NA & \\
\hline Lymph node metastases & 62 & 44.6 & 41 & 46.1 & 11 & 36.7 & 10 & 50.0 & NA & \\
\hline \multicolumn{11}{|l|}{ UICC p-stage } \\
\hline 1 & 40 & 28.7 & 23 & 25.8 & 12 & 40.0 & 5 & 25.0 & NA & \\
\hline 2 & 70 & 50.4 & 49 & 55.1 & 12 & 40.0 & 9 & 45.0 & & \\
\hline 3 & 16 & 11.5 & 8 & 9.0 & 5 & 16.7 & 3 & 15.0 & & \\
\hline 4 & 13 & 9.4 & 9 & 10.1 & 1 & 3.3 & 3 & 15.0 & & \\
\hline Papillary morphology & 32 & 23.0 & 13 & 14.6 & 18 & 60.0 & 1 & 5.0 & NA & \\
\hline Adjuvant chemotherapy & 51 & 36.7 & 34 & 38.2 & 8 & 26.7 & 9 & 45.0 & NA & \\
\hline CEA (high) & 65 & 46.7 & 46 & 51.7 & 12 & 40.0 & 7 & 35.0 & NA & \\
\hline CA19-9 (high) & 66 & 47.5 & 44 & 49.4 & 12 & 40.0 & 10 & 50.0 & NA & \\
\hline LAT1 (high) & 89 & 64.0 & 59 & 66.3 & 18 & 60.0 & 12 & 60.0 & 0 & $0.0 \%$ \\
\hline Ki-67 (high) & 62 & 44.6 & 43 & 48.3 & 13 & 43.3 & 6 & 30.0 & 0 & $0.0 \%$ \\
\hline CD34 (high) & 69 & 49.6 & 46 & 51.7 & 14 & 46.7 & 9 & 45.0 & 0 & $0.0 \%$ \\
\hline p53 (positive) & 71 & 51.1 & 44 & 49.4 & 20 & 66.7 & 7 & 35.0 & 0 & $0.0 \%$ \\
\hline
\end{tabular}

Abbreviation: EHCC Extrahepatic cholangiocarcinoma, GB Gallbladder carcinoma, IHCC Intrahepatic cholangiocarcinoma, UICC International union against cancer, p-stage Pathological stage, CEA Carcinoembryonic antigen, LAT1 L-type amino acid transporter 1, NA Not applicable.

drug). Intraoperative therapy was not performed on any patients. The day of surgery was considered the starting day for measuring postoperative survival. A median follow-up duration for all patients was 18.6 months (range, 3.0 to 110.3 months).

\section{Immunohistochemical analysis}

The immunohistochemical analysis was performed on the 139 primary lesions with cholangiocarcinoma and 16 resected lesions with biliary benign diseases. Figure 1 represents the immunohistochemical staining of LAT1 expression. LAT1 immunostaining was detected in carcinoma cells in tumor tissues and localized predominantly on their plasma membrane. All positive cells revealed strong membranous LAT1 immunostaining. Cytoplasmic staining was rarely evident. The high expression rate and average scoring of LAT1 were compared according to tumor location (Additional file 2:
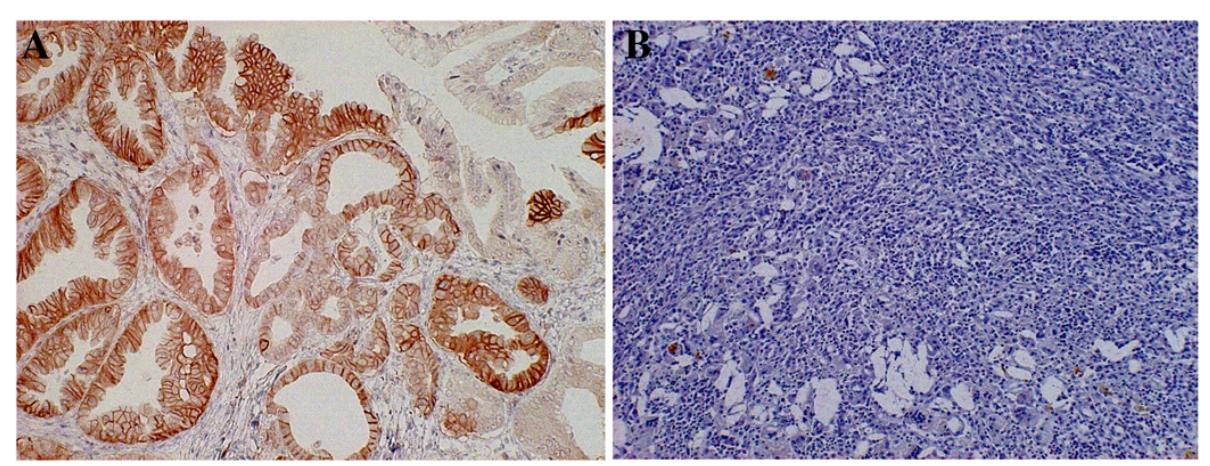

Figure 1 Immunohistochemical staining of tissue from a 79-years old man with extrahepatic cholangiocarcinoma (A) and a 66-years old woman with Xanthogranulomatous chlecystitis as control group (B). Immunostaining of LAT1 demonstrates a membranous immunostaining pattern in cholangiocarcinoma, but there was no evidence of LAT1 staining in xanthogranulomatous chlecystitis. 
Table S2, online only). In total patients, the high expression rate and average scoring of LAT1 were recognized in $64.0 \%$ and $2.7 \pm 0.9$, respectively.

Based on the results of analysis on cholangiocarcinoma, cutoff points for high CD34 expression and high Ki-67 labeling index were defined as follows. The median number of CD34-positive vessels was 21 (range, 4-52), and the value of 21 was chosen as a cutoff point. The median value of the Ki-67 labeling index was 35\% (range, 2-76), and the value of 35\% was chosen as cutoff point. Positive expression of p53 was recognized in $51.1 \%(71 / 139)$. Table 1 shows the expression status of these biomarkers according to tumor location. Rate of high expression or positivity in these biomarkers was significantly higher in cholangiocarcinoma than in biliary benign lesions (Table 1). Patient's demographics according to LAT1 expression status are listed in Table 2. The expression of LAT1 was significantly associated with lymphatic permeation, vascular invasion, lymph node metastasis, CA19-9, Ki-67, and MVD.

Correlation between LAT1 expression and other biomarkers Analysis with Spearman's rank correlation revealed that LAT1 expression was significantly correlated with Ki-67 and CD34 in all tumor location except CD34 in IHCC (Additional file 3: Table S3, online only).

\section{Univariate and multivariate survival analysis}

In all patients, the 5-year survival rate and median survival time (MST) for OS were $35.6 \%$ and 1073 days, respectively, and the 3-year survival rate and MST for PFS was $45.1 \%$ and 840 days, respectively. Because of a postoperative recurrence, 39 patients received systemic chemotherapy using GEM or S-1. Table 3 shows the univariate and multivariate analysis in all patients $(n=139)$. Univariate analysis revealed that significant variables for OS were resected status, tumor differentiation, lymphatic permeation, vascular invasion, lymph nodes metastasis, LAT1, and Ki-67. Significant prognostic markers for PFS by the univariate analysis included resected status, tumor differentiation, lymphatic permeation, vascular invasion, lymph node metastasis, tumor stage, and LAT1. According to the results of univariate log-rank test, we screened prognostic factors with cut-off of $p<0.05$. Multivariate analysis confirmed that lymphatic permeation and a high LAT1 expression, lymphatic permeation and Ki-67 were independent prognostic factors for predicting poor OS,

Table 2 Patient's demographics according to LAT1 expression status

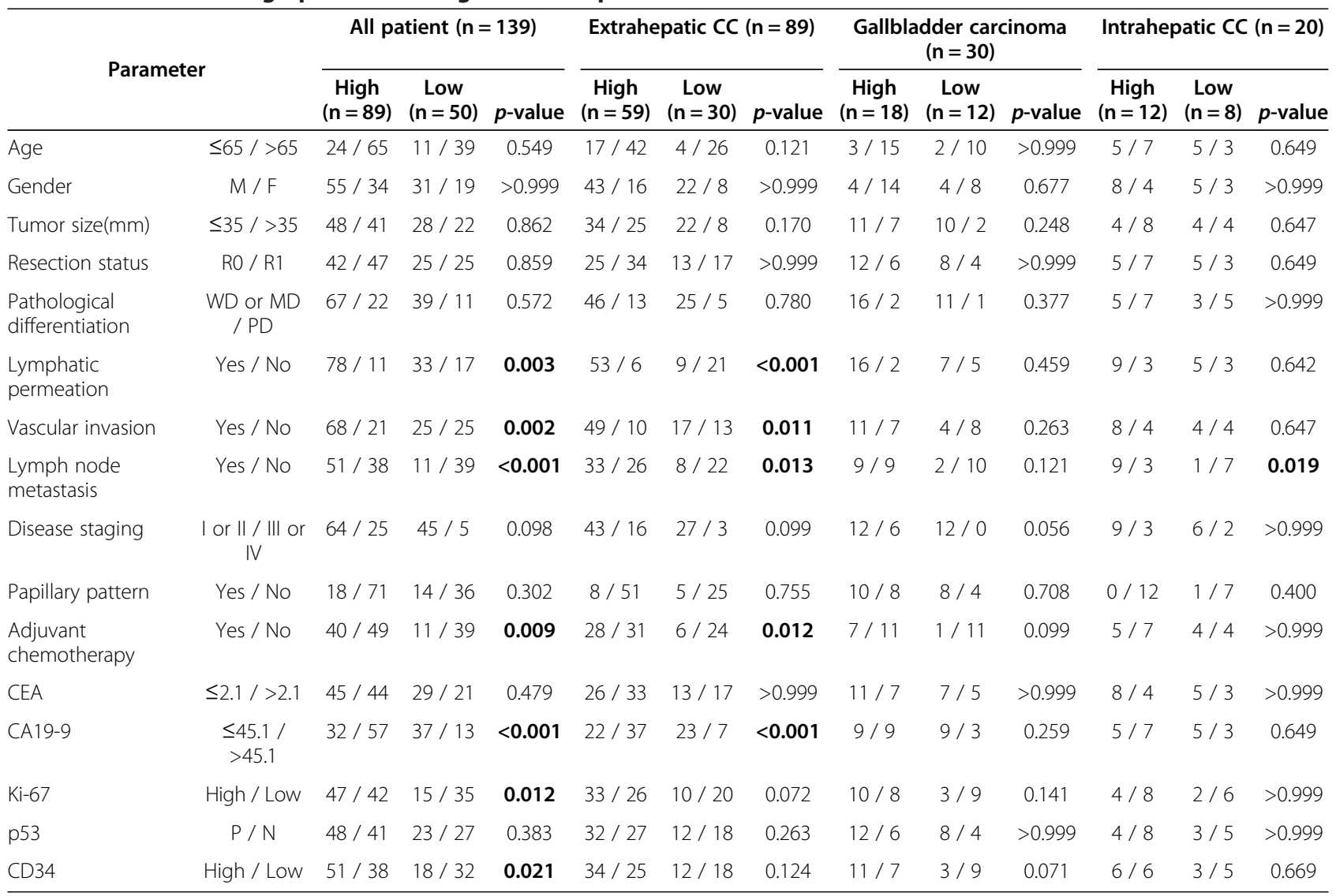

Abbreviation: LAT1 L-type amino acid transporter 1, CC Cholangiocarcinoma, M / F Male / Female, CEA Carcinoembryonic antigen, WD or MD / PD Well differentiated or moderate differentiated / poorly differentiated, $P$ /N Positive / Negative, Bold numbers Statistically significant difference. 
Table 3 Univariate and multivariate analysis in overall survival and progression-free survival

\begin{tabular}{|c|c|c|c|c|c|c|c|c|c|c|}
\hline \multirow[b]{2}{*}{ Variable } & \multicolumn{5}{|c|}{ Overall survival } & \multicolumn{5}{|c|}{ Progression-free survival } \\
\hline & $\begin{array}{l}5 \text {-year } \\
\text { survival rate } \\
(\%)\end{array}$ & $\begin{array}{l}p \text {-value } \\
\text { (univariate) }\end{array}$ & $\begin{array}{l}p \text {-value } \\
\text { (multivariate) }\end{array}$ & $\begin{array}{l}\text { Hazard } \\
\text { ratio }\end{array}$ & $95 \% \mathrm{Cl}$ & $\begin{array}{l}\text { 3-year } \\
\text { survival rate } \\
\text { (\%) }\end{array}$ & $\begin{array}{l}p \text {-value } \\
\text { (univariate) }\end{array}$ & $\begin{array}{l}p \text {-value } \\
\text { (multivariate) }\end{array}$ & $\begin{array}{l}\text { Hazard } \\
\text { ratio }\end{array}$ & $95 \% \mathrm{Cl}$ \\
\hline \multicolumn{11}{|l|}{$\begin{array}{l}\text { Anatomical } \\
\text { locations }\end{array}$} \\
\hline EHCC & 38.1 & 0.837 & & & & 48.3 & 0.395 & & & \\
\hline $\mathrm{IHCC}$ & 28.0 & & & & & 28.2 & & & & \\
\hline GB & 34.5 & & & & & 45.6 & & & & \\
\hline \multicolumn{11}{|l|}{ Age } \\
\hline$\leq 65 \mathrm{yr}$ & 39.9 & 0.095 & & & & 48.4 & 0.707 & & & \\
\hline$>65 \mathrm{yr}$ & 27.5 & & & & & 54.7 & & & & \\
\hline \multicolumn{11}{|l|}{ Gender } \\
\hline Male & 30.2 & 0.267 & & & & 49.7 & 0.634 & & & \\
\hline Female & 33.5 & & & & & 58.6 & & & & \\
\hline Resection & & & & & 0.974 to & & & & & 0.875 to \\
\hline Ro & 42.5 & 0.026 & 0.075 & 1.300 & & 64.2 & 0.016 & 0.310 & 1.154 & 1.535 \\
\hline R1 or R2 & 29.8 & & & & & 40.1 & & & & \\
\hline $\begin{array}{l}\text { Tumor } \\
\text { differentiation }\end{array}$ & & & & & $\begin{array}{l}0.881 \text { to } \\
1.593\end{array}$ & & & & & $\begin{array}{c}0.729 \text { to } \\
1.307\end{array}$ \\
\hline $\begin{array}{r}\text { Well or } \\
\text { moderate }\end{array}$ & 47.3 & 0.017 & 0.251 & 0.190 & & 55.2 & 0.008 & 0.845 & 0.971 & \\
\hline Poorly & 7.8 & & & & & 39.6 & & & & \\
\hline $\begin{array}{l}\text { Lymphatic } \\
\text { permeation }\end{array}$ & & & & & $\begin{array}{l}1.057 \text { to } \\
7.629\end{array}$ & & & & & $\begin{array}{c}1.212 \text { to } \\
10.72\end{array}$ \\
\hline Yes & 19.9 & 0.002 & 0.036 & 2.555 & & 44.9 & $<0.001$ & 0.016 & 3.139 & \\
\hline No & 79.9 & & & & & 81.7 & & & & \\
\hline $\begin{array}{l}\text { Vascular } \\
\text { invasion }\end{array}$ & & & & 0.939 & $\begin{array}{l}0.468 \text { to } \\
1.939\end{array}$ & & & & & $\begin{array}{l}1.073 \text { to } \\
5.057\end{array}$ \\
\hline Yes & 20.5 & 0.011 & 0.862 & & & 40.2 & $<0.001$ & 0.031 & 2.244 & \\
\hline No & 58.7 & & & & & 74.8 & & & & \\
\hline $\begin{array}{l}\text { Lymph nodes } \\
\text { metastasis }\end{array}$ & & & & 0.977 & $\begin{array}{l}0.552 \text { to } \\
1.706\end{array}$ & & & & & $\begin{array}{c}0.517 \text { to } \\
4.534\end{array}$ \\
\hline Positive & 20.5 & 0.041 & 0.935 & & & 41.3 & 0.003 & 0.454 & 1.507 & \\
\hline Negative & 44.0 & & & & & 63.2 & & & & \\
\hline Tumor stage & & & & & & & & & & 0.922 to \\
\hline | or || & 38.2 & 0.051 & & & & 60.1 & 0.003 & 0.088 & 1.685 & 30 \\
\hline III or IV & 29.5 & & & & & 26.8 & & & & \\
\hline LAT1 & & & & & 1.196 to & & & & & 0.785 to \\
\hline High & 20.3 & $<0.001$ & 0.013 & 2.414 & 5 & 41.1 & 0.005 & 0.242 & 1.449 & $2.83 /$ \\
\hline Low & 59.3 & & & & & 71.3 & & & & \\
\hline Ki-67 & & & & & 1.030 to & & & & & \\
\hline High & 29.6 & 0.021 & 0.038 & 1.781 & 3.093 & 49.2 & 0.192 & & & \\
\hline Low & 36.2 & & & & & 53.6 & & & & \\
\hline p53 & & & & & & & & & & \\
\hline Positive & 21.3 & 0.119 & & & & 54.1 & 0.831 & & & \\
\hline Negative & 38.1 & & & & & 51.6 & & & & \\
\hline
\end{tabular}



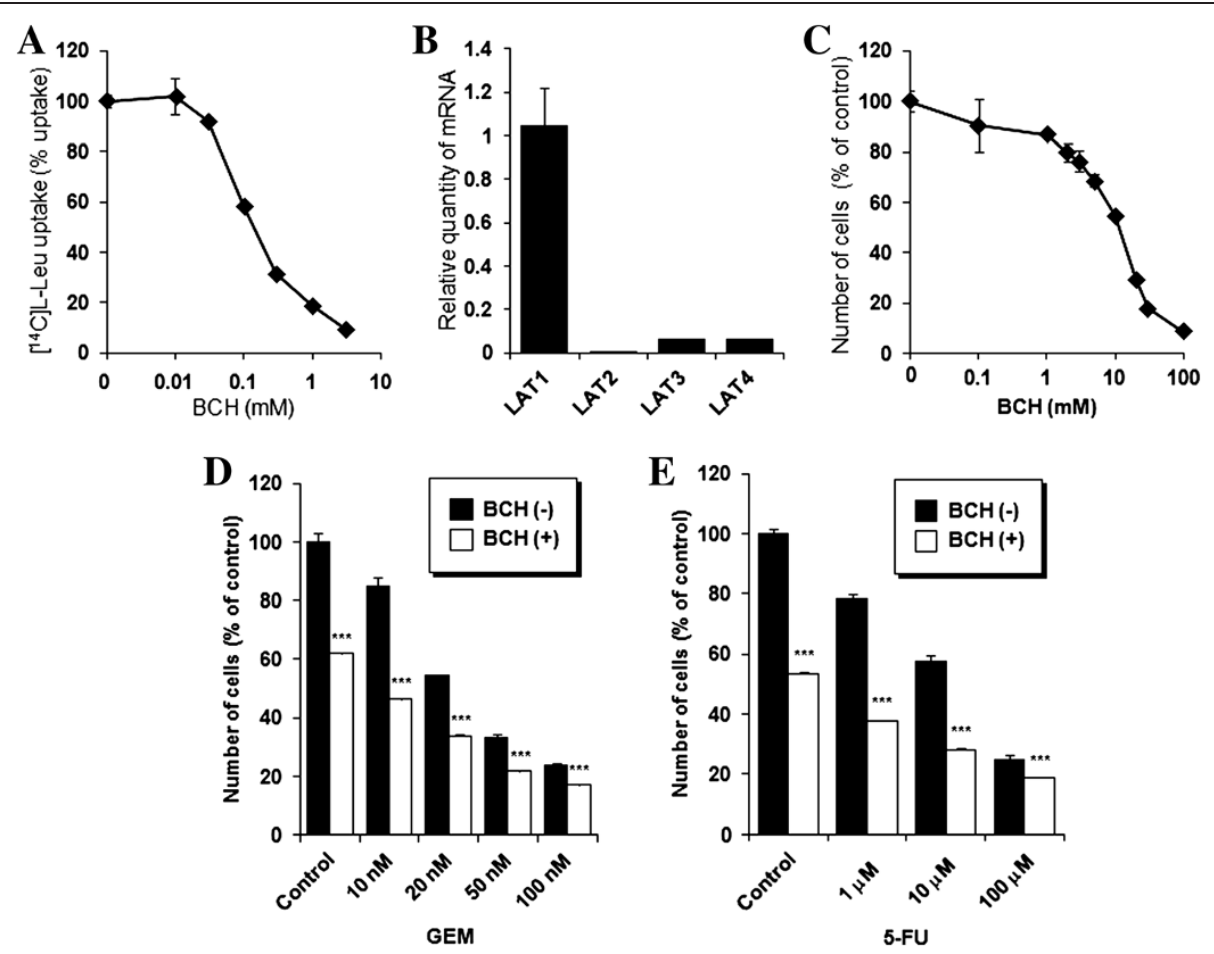

Figure 3 Effect of LAT inhibition on in vitro cellular proliferation and anti-tumor activity of GEM and 5-FU: (A) BCH inhibits $\left[{ }^{14} \mathrm{C}\right] \mathrm{L}-\mathrm{leucine}$ uptake concentration-dependently in HuCCT1 cells $(n=4)$. Ordinate shows a percentage of $\left[{ }^{14} \mathrm{C}\right] \mathrm{L}$-leucine uptake in the absence of $\mathrm{BCH}$ as a control. (B) Expression of LAT1, LAT2, LAT3, and LAT4 mRNA in HuCCT1 cells $(n=4)$. Ordinate shows relative quantity of mRNA calibrated by LAT1 mRNA. (C) BCH decreases number of HuCCT1 cells concentration-dependently $(n=4)$. Ordinate shows number of cells in a percentage of control (without BCH). Addition of $10 \mathrm{mM} \mathrm{BCH}$ enhances anti-tumor effect of GEM (D) and 5-FU (E) on HuCCT1 cells. Ordinate shows number of cells in a percentage of control $(n=4)$. A statistically significant difference from the control is indicated by *** $(P<0.001)$.

indicator for predicting poor outcome after surgical resection. Therefore, a high LAT1 expression may play an important role on the growth of biliary tract cancer. No anatomic site-related differences were observed for LAT1. Results of our preliminary experiments indicated that the inhibition of LAT1 had significant anti-tumor effect on cholangiocarcinoma with acceptable toxicity and yielded an additive therapeutic efficacy to GEM and 5-FU. Our data suggests that LAT1 inhibition suppresses the growth of biliary tract cancer and LAT1 could be a potential target for locally advanced or metastatic biliary tract cancer.

Recently, two studies have exhibited the significance of LAT1 expression as a prognostic predictor in pancreatic cancer $[33,34]$. In pancreatic cancer, LAT1 was highly expressed in $52.6 \%$ [33]. In biliary tract cancer, the ratio of high LAT1 expression yielded a similar tendency among all anatomic site (EHCC, IHCC, and GB). These results indicate that the expression of LAT1 is higher in biliary tract cancer than pancreatic cancer. The LAT1 expression is variable in human cancers, and relatively low in adenocarcinoma, for example, $29 \%$ in pulmonary adenocarcinoma [12], 22\% in prostate cancer [15], 43\% in breast cancer [17], and $43 \%$ in gastric cancer [16].
LAT1 seemed to be expressed at higher level in biliary tract adenocarcinoma than in adenocarcinoma of the other organs. Therefore, LAT1 may play a crucial role in enhancing the cell proliferation and tumor growth in biliary tract cancer.

Recently, we had evaluated the protein expression of LAT1 by immunohistochemistry in patients with pulmonary neuroendocrine tumors [35]. Our data indicated that the expression of LAT1 tended to increase from lowgrade to high-grade malignancies. Moreover, we confirmed the different expression of LAT1 between pancreatic cancer and pancreatic adenoma, showing that LAT1 expression was not observed in pancreatic adenoma, whereas LAT1 was highly expressed in pancreatic cancer [33]. Previous experimental data also demonstrated that LAT1 is overexpressed in tumor cells and LAT2 is dominantly expressed in normal cells $[9,10]$. In the protein expression level of human tissue specimens, there was no evidence of LAT1 expression in normal tissues. Thus, we believe that LAT1 is tumor-specific amino acid transporter and has a potential target of cancer therapeutics.

This study investigated the therapeutic potential of LAT1 inhibition in cholangiocarcinoma. We found that $\mathrm{BCH}$ as a competitive LAT inhibitor suppressed 

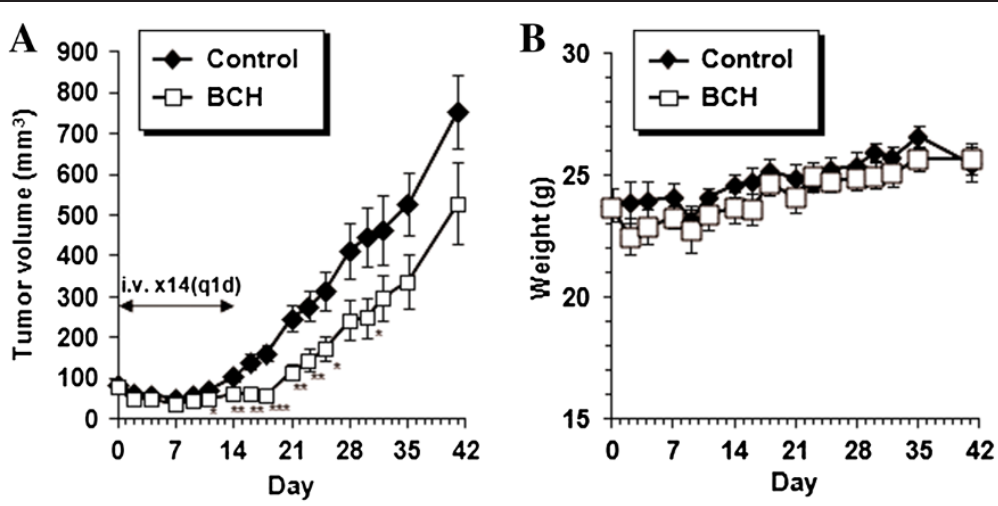

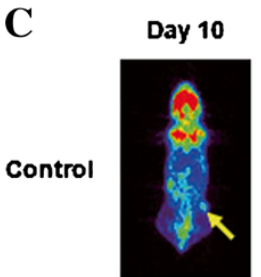

SUV max

SUV $\mathbf{5 0} \%$

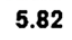

3.73

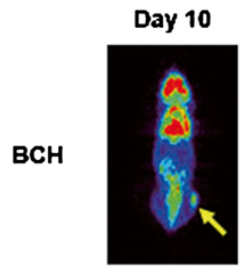

SUV max

SUV $\mathbf{5 0} \%$

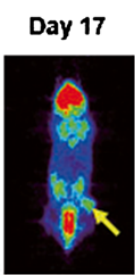

9.71

6.07

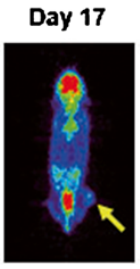

4.27

2.29

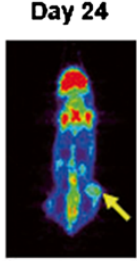

10.59

6.71

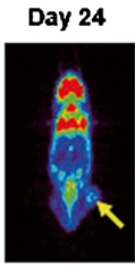

8.34

5.08

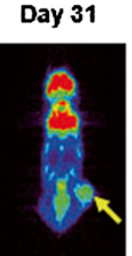

12.27

6.23

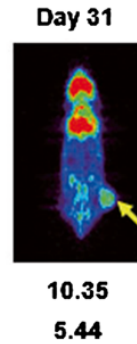

$20 \mathrm{MBq} / \mathrm{ml}$

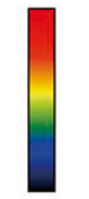

O MBq/ml

$20 \mathrm{MBq} / \mathrm{ml}$

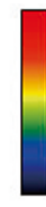

O MBq/ml

Figure 4 In vivo anti-tumor effect of LAT inhibition on cholangiocarcinoma xenograft. (A) Intravenous administration of BCH shows delay in the growth of HuCCT1 tumor $(n=10)$. A statistically significant difference from the control is indicated by * $(P<0.05)$, ** $(P<0.01)$, and ${ }^{* * *}(P<0.001)$. (B) Changes in the body weight of HuCCT1 tumor-bearing mice after administration of $B C H(n=10)$. (C) Representative coronal section of ${ }^{18} \mathrm{~F}$-FDG PET images of HuCCT1-bearing mice at $2 \mathrm{~h}$ after ${ }^{18} \mathrm{~F}$-FDG injection. PET imaging was performed at indicated day after the day of grouping $(n=2)$. The calibration bar is shown at right-side of images. SUV max and SUV 50\% are shown below the images.

proliferation of cholangiocarcinoma cells and yielded an additive therapeutic efficacy to GEM and 5-FU in vitro. Moreover, in vivo experiment demonstrated significant growth suppression of tumor with acceptable toxicity. Recent reports also showed that the inhibition of LAT activity by $\mathrm{BCH}$ resulted in the suppression of cell proliferation in various cancers $[9,13,19,20]$. Nawashiro et al. showed that $\mathrm{BCH}$ reduced mortality of $\mathrm{C} 6$ gliomabearing rat model, and suggested that LAT1 inhibitors could be an effective therapeutic option for high-grade gliomas [14]. Kim et al. reported that $\mathrm{BCH}$ could lead to apoptosis by inducing intracellular depletion of amino acids required for the growth of cancer cells [20]. Liu et al. described that $\mathrm{BCH}$ induced apoptosis without affecting DNA synthesis in proliferating vascular smooth muscle cells, whereas it had no effect on quiescent smooth muscle cells. Therefore, the inhibition of
LAT1 gives rise to growth inhibition effects of highly proliferative cells that require increased amino acid metabolism [36]. Another proposed mechanism of action is cell cycle arrest at G1 phase by the inhibition of LAT1 [37]. However, there is no established explanation regarding the in vivo anti-tumor effect of LAT1 inhibitor, although there are two preclinical studies investigating the potential of LAT1 inhibitor in tumor xenografts (glioma [13] and cholangiocarcinoma [current study]). Further in vivo study is warranted to evaluate whether a combination of GEM plus LAT1 inhibitor is effective for biliary tract cancer xenograft compared to GEM alone as seen in the current in vitro study that has been demonstrating effect of GEM plus BCH.

A recent systemic review has suggested that p53 mutation, cyclins, proliferation indices (Ki-67), mucins, CA199, and CEA have potential as prognostic predictors in 
cholangiocarcinoma [38], however, there is no targeting therapy for these molecules at present. Recently, antiepidermal growth factor receptor (EGFR) agents, mitogen-activated protein kinase/extracellular-signal regulated kinase (MEK) inhibitors, and anti-angiogenic agents have been thought to be the promising targeted agents for biliary tract cancer [39]. However, the results of clinical trials indicated no therapeutic efficacy to improve the survival of patients with advanced biliary tract cancer [39].

\section{Conclusion}

In conclusion, high expression of LAT1 plays an important role in enhancing tumor growth and cell proliferation and is a promising pathological marker for predicting poor prognosis in patients with biliary tract cancer. The inhibition of LAT significantly suppressed the growth of cholangiocarcinoma, and anti-tumor efficacy of GEM and 5-FU was augmented in combination with LAT inhibitor. Since the LAT1 expression is a significant prognostic marker and LAT1 inhibition probably has anti-tumor efficacy, molecular targeting drug that selectively inhibit LAT1 will aid in the promising therapeutic strategy for bile duct cancer.

\section{Additional files}

Additional file 1: Table S1. Primers for realtime RT-PCR used in the present study.

Additional file 2: Table S2. Comparison of percentage of high expression and average score of LAT1.

Additional file 3: Table S3. Correlation between LAT1 expression and various biomarkers.

Additional file 4: Figure S1. Expression of LAT1 and CD98 in human cholangiocarcinoma cell lines (HuCCT1, OZ and HuH28). Representative images from three independent experiments are shown. $\beta$-actin was shown as a control.

\section{Abbreviations}

LAT1: L-type amino acid transporter 1; BCH: 2-aminobicyclo-(2,2,1)-heptane-2carboxylic acid; MRCP: Magnetic resonance cholangiopancreatography; ERCP: Endoscopic retrograde cholangiopancreatography; EHCC: Extrahepatic cholangiocarcinoma; IHCC: Intrahepatic cholangiocarcinoma; GB: Gallbladder carcinoma; TNM: Pathologic tumor-node-metastasis; MVD: Microvessel density; DMEM: Dulbecco's modified Eagle's medium; MTT: 3-[4,5-dimethyl-2thiazolyl]-2,5-diphenyl-2H-tetrazolium bromide; GEM: Gemcitabine; 5-FU: 5-fluorouracil; ${ }^{18} \mathrm{~F}$-FDG: $\left[{ }^{18} \mathrm{~F}\right]$ fluoro-2-deoxyglucose; PET: Positron emission tomography; ROI: Region of interest; SUV: Standardized uptake value; OS: Overall survival; PFS: Progression-free survival; MST: Median survival time; EGFR: Epidermal growth factor receptor; MEK: Mitogen-activated protein kinase/extracellular-signal regulated kinase.

\section{Competing interests}

We, all authors, have no financial or personal relationships with other people or organizations that could inappropriately influence our work. The authors declare that they have no competing interests.

\section{Authors' contributions}

KK, YS, YO, NSI, HT, NO and KA have made substantial contributions to conception and design, or acquisition of data, or analysis and interpretation of data; KK, YO, YK, TO, KS, NS, HI, SN, AY, AS and MI have been involved in drafting the manuscript or revising it critically for important intellectual content; and KK, YO, TO, MM and IT have given final approval of the version to be published. All authors read and approved the final manuscript.

\section{Acknowledgements}

This work was supported in part by Grant 23591750 (K. K) and 25461801 (N.O) from the Ministry of Education, Culture, Sports, Science and Technology, Japan, and National Hospital Organization Policy Based Medical Services. We thank Ms. Masako Saito for their technical assistance of immunohistochemical analysis. Advanced research for medical products Mining Programme of the National Institute of Biomedical Innovation (NIBIO).

\section{Author details}

${ }^{1}$ Department of Medicine and Molecular Science, Gunma University Graduate School of Medicine, Showa-machi, Maebashi, Gunma, Japan. ${ }^{2}$ Department of Thoracic and Visceral Surgery, Gunma University Graduate School of Medicine, Showa-machi, Maebashi, Gunma, Japan. ${ }^{3}$ Medical Radioisotope Application Group, Quantum Beam Science Directorate, Japan Atomic Energy Agency, Watanuki, 370-1292 Takasaki, Gunma, Japan. ${ }^{4}$ Department of Surgery, Maebashi Red Cross Hospital, Asahi-cho, Maebashi, Gunma, Japan. ${ }^{5}$ Department of Molecular Imaging, Gunma University Graduate School of Medicine, Showa-machi, Maebashi, Gunma, Japan. ${ }^{6}$ Department of Diagnostic Radiology and Nuclear Medicine, Gunma University Graduate School of Medicine, Showa-machi, Maebashi, Gunma, Japan. 'Department of Radiology, Saku Central Hospital, Usuda, Saku, Nagano, Japan. ${ }^{8}$ Department of Pathology, Maebashi Red Cross Hospital, Asahi-cho, Maebashi, Gunma, Japan. 'Division of Bio-system Pharmacology, Department of Pharmacology, Graduate School of Medicine, Osaka University, Osaka, Japan. ${ }^{10}$ Department of Bioimaging Information Analysis, Gunma University Graduate School of Medicine, Showa-machi, Maebashi, Gunma, Japan. ${ }^{11}$ Department of Diagnostic Pathology, Gunma University Graduate School of Medicine, Showa-machi, Maebashi, Gunma, Japan. ${ }^{12}$ Oncology Center, Gunma University Hospital Showa-machi, 371-8511 Maebashi, Gunma, Japan.

Received: 27 April 2013 Accepted: 25 September 2013 Published: 16 October 2013

References

1. Khan SA, Taylor-Robinson SD, Toledano MB, Beck A, Elliott P, Thomas HC: Changing international trends in mortality rates for liver, biliary and pancreatic tumors. J Hepatol 2002, 37:806-813.

2. Nakeeb A, Pitt HA, Sohn TA, Coleman J, Abrams RA, Piantadosi S, Hruban $\mathrm{RH}$, Lillemoe KD, Yeo CJ, Cameron JL: Cholangiocarcinoma. A spectrum of intrahepatic, perihilar, and distal tumors. Ann Surg 1996, 22:463-475.

3. Nakagohri T, Kinoshita T, Konishi M, Takahashi S, Gotohda N: Surgical outcome and prognostic factors in intrahepatic cholangiocarcinoma. World J Surg 2008, 32:2675-2680.

4. Hirano S, Kondo S, Tanaka E, Shichinohe T, Tsuchikawa T, Kato K, Matsumoto J, Kawasaki R: Outcome of surgical treatment of hilar cholangiocarcinoma: a special reference to postoperative morbidity and mortality. J Hepatobiliary Pancreat Sci 2010, 17:455-462.

5. Sakamoto Y, Kosuge T, Shimada K, Sano T, Ojima H, Yamamoto J, Yamasaki S, Takayama T, Makuuchi M: Prognostic factors of surgical resection in middle and distal bile duct cancer: an analysis of 55 patients concerning the significance of ductal and radial margins. Surgery 2005, 37:396-402.

6. Valle J, Wasan $\mathrm{H}$, Palmer DH, Cunningham D, Anthoney A, Maraveyas A, Madhusudan S, Iveson T, Hughes S, Pereira SP, Roughton M, Bridgewater J: $A B C-02$ trial investigators: cisplatin plus gemcitabine versus gemcitabine for biliary tract cancer. N Engl J Med 2010, 362:1273-1281.

7. Christensen HN: Role of amino acid transport and countertransport in nutrition and metabolism. Physiol Rev 1990, 70:43-77.

8. McGivan JD, Pastor-Anglada M: Regulatory and molecular aspects of mammalian amino acid transport. Biochem J 1994, 299:321-334.

9. Kanai Y, Segawa H, Miyamoto K, Uchino H, Takeda E, Endou H: Expression cloning and characterization of a transporter for large neutral amino acids activated by the heavy chain of 4F2 antigen (CD98). J Biol Chem 1998, 273:23629-23632.

10. Yanagida O, Kanai $Y$, Chairoungdua A, Kim DK, Segawa H, Nii T, Cha SH, Matsuo H, Fukushima J, Fukasawa Y, Tani Y, Taketani Y, Uchino H, Kim JY, Inatomi J, Okayasu I, Miyamoto K, Takeda E, Goya T, Endou H: Human 
L-type amino acid transporter 1 (LAT 1): characterization of function and expression in tumor cell lines. Biochim Biophys Acta 2001, 1514:291-302.

11. Kobayashi H, Ishii Y, Takayama T: Expression of L-type amino acid transporter 1 (LAT1) in esophageal carcinoma. J Surg Oncol 2005, 90:233-238.

12. Kaira K, Oriuchi N, Imai H, Shimizu K, Yanagitani N, Sunaga N, Hisada T, Tanaka S, Ishizuka T, Kanai Y, Endou H, Nakajima T, Mori M: Prognostic significance of L-type amino acid transporter 1 expression in resectable stage I-III nonsmall cell lung cancer. Br J Cancer 2008, 98:742-748.

13. Nakanishi K, Ogata S, Matsuo H, Kanai Y, Endou H, Hiroi S, Tominaga S, Aida S, Kasamatsu H, Kawai T: Expression of LAT1 predicts risk of progression of transitional cell carcinoma of the upper urinary tract. Virchows Arch 2007, 451:681-690.

14. Nawashiro H, Otani N, Shinomiya N, Fukui S, Ooigawa H, Shima K, Matsuo H, Kanai Y, Endou H: L-type amino acid transporter 1 as a potential molecular target in human astrocytic tumors. Int J Cancer 2006, 119:484-492.

15. Sakata T, Ferdous G, Tsuruta T, Satoh T, Baba S, Muto T, Ueno A, Kanai $Y$, Endou $\mathrm{H}$, Okayasu I: L-type amino acid transporter 1 as a novel biomarker for high-grade malignancy in prostate cancer. Pathol Int 2009, 59:7-18.

16. Ichinoe M, Mikami T, Yoshida T, Igawa I, Tsuruta T, Nakada N, Anzai N, Suzuki Y, Endou H, Okayasu I: High expression of L-type amino-acid transporter 1 (LAT1) in gastric carcinomas: comparison with non-cancerous lesions. Pathol Int 2011, 61:281-289.

17. Furuya $M$, Horiguchi J, Nakajima $H$, Kanai $Y$, Oyama T: Correlation of L-type amino acid transporter 1 and CD98 expression with triple negative breast cancer prognosis. Cancer Sci 2012, 103:382-389.

18. Kaira K, Oriuchi N, Takahashi T, Nakagawa K, Ohde Y, Okumura T, Murakami H, Shukuya T, Kenmotsu H, Naito T, Kanai Y, Endo M, Kondo H, Nakajima T, Yamamoto N: LAT1 expression is closely associated with hypoxic markers and mTOR in resected non-small cell lung cancer. Am J Trans/ Res 2011, 3:468-478.

19. Kaira K, Oriuchi N, Takahashi T, Nakagawa K, Ohde Y, Okumura T, Murakami H, Shukuya T, Kenmotsu H, Naito T, Kanai Y, Endo M, Kondo H, Nakajima T, Yamamoto N: L-type amino acid transporter 1 (LAT1) expression in malignant pleural mesothelioma. Anticancer Res 2011, 31:4075-4082.

20. Kim CS, Cho SH, Chun HS, Lee SY, Endou H, Kanai Y, Kim do K: BCH, an inhibitor of system $L$ amino acid transporters, induces apoptosis in cancer cells. Biol Pharm Bull 2008, 31:1096-1100.

21. Imai H, Kaira K, Oriuchi N, Shimizu K, Tominaga H, Yanagitani N, Sunaga N, Ishizuka T, Nagamori S, Promchan K, Nakajima T, Yamamoto N, Mori M, Kanai Y: Inhibition of L-type amino acid transporter 1 has antitumor activity in non-small cell lung cancer. Anticancer Res 2010, 30:4819-4828.

22. Sobin LH, Gospodarowicz MK, Wittekind C (Eds): International Union Against Cancer (UICC) TNM Classification of Malignant Tumors. 7th edition. Oxford, UK: Wiley-Blackwell; 2009

23. Kaira K, Oriuchi N, Imai H, Shimizu K, Yanagitani N, Sunaga N, Hisada T, Kawashima O, Kamide Y, Ishizuka T, Kanai Y, Nakajima T, Mori M: CD98 expression is associated with poor prognosis in resected non-small-cell lung cancer with lymph node metastases. Ann Surg Oncol 2009, 16:3473-3581.

24. Kaira $K$, Endo $M$, Abe M, Nakagawa $K$, Ohde $Y$, Okumura T, Takahashi T, Murakami H, Tsuya A, Nakamura Y, Naito T, Hayashi I, Serizawa M, Koh Y, Hanaoka $\mathrm{H}$, Tominaga $\mathrm{H}$, Oriuchi $\mathrm{N}$, Kondo $\mathrm{H}$, Nakajima T, Yamamoto $\mathrm{N}$ : Biologic correlation of 2-[ $\left.{ }^{18} \mathrm{~F}\right]$-fluoro-2-deoxy-D-glucose uptake on positron emission tomography in thymic epithelial tumors. J Clin Oncol 2010, 28:3746-3753.

25. Miyagiwa M, Ichida T, Tokiwa T, Sato J, Sasaki H: A new human cholangiocellular carcinoma cell line (HuCC-T1) producing carbohydrate antigen 19/9 in serum-free medium. In Vitro Cell Dev Biol 1989, 25:503-510.

26. Homma S, Nagamori S, Fujise K, Yamazaki K, Hasumura S, Sujino H, Matsuura T, Shimizu K, Kameda H, Takaki K: Human bile duct carcinoma cell line producing abundant mucin in vitro. Gastroenterol Jpn 1987, 22:474-479.

27. Kusaka Y, Tokiwa T, Sato J: Establishment and characterization of a cell line from a human cholangiocellular carcinoma. Res Exp Med (Berl) 1988, 188:367-375.

28. Segawa H, Fukasawa $Y$, Miyamoto $K$, Takeda E, Endou H, Kanai Y: Identification and functional characterization of a $\mathrm{Na}+-$-independent neutral amino acid transporter with broad substrate selectivity. J Biol Chem 1999, 274:19745-19751.

29. Babu E, Kanai Y, Chairoungdua A, Kim DK, Iribe Y, Tangtrongsup S, Jutabha P, Li Y, Ahmed N, Sakamoto S, Anzai N, Nagamori S, Endou H: Identification of a novel system $L$ amino acid transporter structurally distinct from heterodimeric amino acid transporters. J Bio/ Chem 2003, 273:43838-43845.

30. Bodoy S, Martín L, Zorzano A, Palacín M, Estévez R, Bertran J: Identification of LAT4, a novel amino acid transporter with system $L$ activity. J Biol Chem 2005, 280:12002-12011.

31. Kim DK, Kanai Y, Choi HW, Tangtrongsup S, Chairoungdua A, Babu E, Tachampa K, Anzai N, Iribe Y, Endou H: Characterization of the system L amino acid transporter in T24 human bladder carcinoma cells. Biochim Biophys Acta 2002, 1565:112-121.

32. Morimoto E, Kanai Y, Kim do K, Chairoungdua A, Choi HW, Wempe MF, Anzai N, Endou H: Establishment and characterization of mammalian cell lines stably expressing human L-type amino acid transporters. J Pharmacol Sci 2008, 108:505-516.

33. Kaira K, Sunose Y, Arakawa K, Ogawa T, Sunaga N, Shimizu K, Tominaga H, Oriuchi N, Itoh H, Nagamori S, Kanai Y, Segawa A, Furuya M, Mori M, Oyama T, Takeyoshi I: Prognostic significance of L-type amino-acid transporter 1 expression in surgically resected pancreatic cancer. Br J Cancer 2012, 107:632-638.

34. Yanagisawa N, Ichinoe M, Mikami T, Nakada N, Hana K, Koizumi W, Endou H, Okayasu I: High expression of L-type amino acid transporter 1 (LAT1) predicts poor prognosis in pancreatic ductal adenocarcinomas. J Clin Pathol 2012, 65:1019-1023.

35. Kaira K, Oriuchi N, Imai H, Shimizu K, Yanagitani N, Sunaga N, Hisada T, Kawashima $\mathrm{O}$, lijima $\mathrm{H}$, Ishizuka $\mathrm{T}$, Kanai $\mathrm{Y}$, Endou $\mathrm{H}$, Nakajima T, Mori M: Expression of L-type amino acid transporter 1 (LAT1) in neuroendocrine tumors of the lung. Pathol Res Pract 2008, 204:553-561.

36. Liu XM, Reyna SV, Ensenat D, Peyton KJ, Wang H, Schafer Al, Durante W: Platelet-derived growth factor stimulates LAT1 gene expression in vascular smooth muscle: role in cell growth. FASEB J 2004, 18:768-770.

37. Kim CS, Moon IS, Park JH, Shin WC, Chun HS, Lee SY, Kook JK, Kim HJ, Park JC Endou $H$, Kanai $Y$, Lee BK, Kim do K: Inhibition of L-type amino acid transporter modulates the expression of cell cycle regulatory factors in KB oral cancer cells. Biol Pharm Bull 2010, 33:1117-1121.

38. Briggs CD, Neal CP, Mann CD, Steward WP, Manson MM, Berry DP: Prognostic molecular markers in cholangiocarcinoma: a systemic review. Eur J Cancer 2009, 45:33-47.

39. Faris JE, Zhu AX: Targeted therapy for biliary tract cancers. J Hepatobiliary Pancreat Sci 2012. Feb 09. [Epub ahead of print].

\section{doi:10.1186/1471-2407-13-482}

Cite this article as: Kaira et al:: Clinical significance of L-type amino acid transporter 1 expression as a prognostic marker and potential of new targeting therapy in biliary tract cancer. BMC Cancer 2013 13:482.

\section{Submit your next manuscript to BioMed Central and take full advantage of:}

- Convenient online submission

- Thorough peer review

- No space constraints or color figure charges

- Immediate publication on acceptance

- Inclusion in PubMed, CAS, Scopus and Google Scholar

- Research which is freely available for redistribution 